\title{
LA INFLUENCIA DE HESÍODO EN LA PROPUESTA PLATÓNICA DEL ESTADO IDEAL
}

Recibido: $14-12-2016$

Aprobado: 26-03-2017

\author{
Úrsula Carrión Caravedo \\ Pontificia Universidad Católica del Perú \\ Universidad del Pacífico
}

Licenciada y Magíster en Filosofía por la Pontificia Universidad Católica del Perú (PUCP) y candidata al Doctorado de Filosofía de la UNED. Enseña cursos de Filosofía y de Lenguaje en la PUCP y la Universidad del Pacífico. Ha colaborado en la edición y corrección de diversos libros y revistas, tanto especializados como de enseñanza y de divulgación. También ha participado en varios congresos de Filosofía y publicado artículos académicos y ensayos. carrion_u@up.edu.pe

\begin{abstract}
Resumen
El objetivo de este texto consiste en mostrar las referencias a Hesíodo presentes en la propuesta de Estado ideal planteada por Platón en la República. Para ello, muestra primero la similitud entre la necesidad platónica por explicar la configuración de la polis ideal a partir de un relato sobre el origen de su formación y el intento de Hesíodo por narrar, desde sus inicios, el surgimiento de todo lo que existe. En segundo lugar, se resalta la influencia del mito hesiódico de los metales en la concepción de la estructura del Estado justo propuesta por Platón. Por último, se presentan las semejanzas entre el gobierno del filósofo y la labor soberana de Zeus.
\end{abstract}

Palabras clave: mito, Estado, jerarquía, justicia, principio

\begin{abstract}
The purpose of this paper is to show the references to Hesiod in Plato's ideal state proposal in the Republic. In order to do this, we first show the similarity between the Platonic need to explain the ideal state with a story about its origin and Hesiod's attempt to narrate, since its beginning, the emergence of everything. Secondly, we emphasize the influence of Hesiod's myth of metals in the design of the state structure proposed by Plato. Finally, we present the similarities between the government of the philosopher and Zeus' sovereignty.
\end{abstract}

Key words: myth, State, hierarchy, justice, principle

La mayoría de estudiosos de la historia de la filosofía coincide en plantear que esta se origina con la superación del discurso mítico. Desde esa perspectiva, Tales de Mileto es considerado el primer filósofo porque buscó explicar la naturaleza y sus orígenes ya no mediante un relato sobre las relaciones y hazañas de las divinidades. Por el contrario, a partir de la observación y el estudio de la naturaleza, propuso una hipótesis sobre el principio del que habría surgido todo el orden: el agua. Los sucesores de Tales continúan esta tradición que, según los estudiosos, sustituye el 
mito por un discurso que incorpora nuevos conceptos y mayor abstracción.

Sin embargo, la ruptura entre el mito y el pensamiento filosófico no parece ser tan radical como algunos creen. El propio Aristóteles, quien considera a Tales iniciador de la reflexión filosófica, señala en la Metafísica lo siguiente: "Ahora bien, el que se siente perplejo y maravillado reconoce que no sabe (de ahí que el amante del

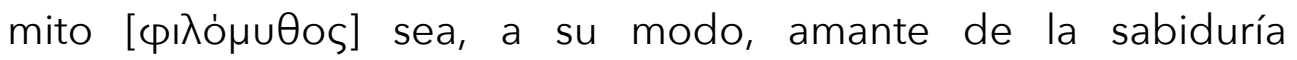

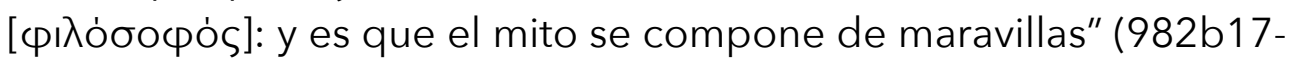
19). Este pasaje revela la existencia de al menos un rasgo común entre quienes valoran el mito y los amantes de la sabiduría, a saber, la capacidad de asombro por lo inexplicable, que es justamente la que los motiva a buscar distintas clases de respuestas (de carácter mítico o filosófico).

En general, el desarrollo de la filosofía no ha implicado un destierro del mito, como observaremos ahora a propósito de Platón. Nuestra intención, de modo más específico, es concentrarnos en las referencias a Hesíodo que aparecen en la propuesta de Estado ideal planteada por el filósofo en la República. Para ello mostraremos, en primer lugar, la similitud entre la explicación platónica del Estado ideal a partir de un relato sobre su origen y la narración Hesíodo sobre cómo surgió, desde un inicio, la totalidad de las cosas. En segundo lugar, resaltaremos la influencia del mito hesiódico de los metales en la estructura de la polis justa propuesta por Platón. Por último, presentaremos las semejanzas entre el gobierno del filósofo y la labor soberana de Zeus.

Se suele afirmar que Platón destierra a los poetas de su polis ideal. No obstante, ya desde el carácter literario de su obra es posible encontrar cierta cercanía con el mito. Gadamer precisa al respecto que Platón "supo unir la herencia racional de su maestro Sócrates con la tradición mítica de la religión popular" (Gadamer, 1997: 27). En efecto, los diálogos platónicos, al igual que los mitos, son narraciones que incorporan personajes. Sin embargo, al mismo tiempo incluyen conversaciones en las que se despliega o se exige una gran consistencia argumentativa -de ahí su herencia socrática.

Por otro lado, no son pocas las alusiones a los poetas y mitos que hace Platón a lo largo de la República. Ya desde el Libro I 
encontramos, por ejemplo, referencias a Sófocles o Píndaro. Posteriormente, en el Libro II, Glaucón menciona a Esquilo y Adimanto recuerda al sabio Arquíloco. Platón además hace uso de leyendas que forman parte de la tradición a la que pertenece, como el relato sobre Giges (359d - 360b). Estos son solo unos pocos ejemplos de los múltiples pasajes en que el filósofo griego se refiere tanto a la tradición poética como a la mitología en general.

Sin embargo, no es el objetivo de este trabajo analizar estas referencias. Nos interesa, más bien, resaltar que Platón reconoce la importancia de la poesía y del mito para los griegos. Al respecto, Szlezák señala lo siguiente:

Es cierto que el fin último del filósofo es la penetración dialéctica de la realidad que se cumple en el logos argumentador. Pero no puede renunciar, sin embargo, a la fuerza psicagógica del mito; además, la capacidad de las imágenes e historias de presentar un contenido de forma global e intuitiva es un complemento imprescindible del análisis conceptual. Visto así, el mito aparece como una segunda vía de acceso a la realidad que ciertamente, en cuanto al contenido, no puede ser independiente del logos, pero que ofrece, sin embargo, frente a él un plus que no puede ser sustituido por nada (Szlezák, 1991: 142).

Platón parece ser consciente del poder del mito y de su presencia en el proceso educativo de los griegos (Cfr. Jaeger, 1957: 150). El filósofo no destierra esta tradición: recurre a los poetas y toma de ellos ciertas cosas, pero deja de lado otras. En el Libro III, por ejemplo, le da la razón a Homero cuando afirma que los gobernados deben obedecer: "Diremos, entonces, que están bien dichas palabras como las que Homero pone en boca de Diomedes: siéntate callado, amigo, y obedece la orden" (389e). Al mismo tiempo, critica los versos homéricos que expresan una ausencia de moderación. Revisemos, por ejemplo, el pasaje 390ab: 
en pan y carne, mientras el escanciador saca el vino de la crátera, lo lleva y lo vierte en las copas,

¿crees que para un joven es apropiado escuchar tales cosas en cuanto a su templanza?"

En suma, no hay en la obra platónica un repudio cabal a los poetas ni un destierro de los mitos. Y esto se hace más evidente cuando el personaje de Sócrates, en la República (376d-e), se refiere a su propio discurso como una suerte de mitologización: "Adelante,

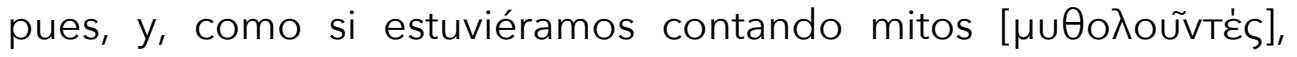
mientras tengamos tiempo para ello, eduquemos en teoría a nuestros hombres".

Veamos a continuación, de modo más concreto, cómo la tradición mitológica de Hesíodo le sirve a Platón para educar a las personas en su concepción de la polis ideal. Lo primero que vale la pena resaltar es la intención de establecer un origen del Estado. En el Libro II de la República, Sócrates anuncia lo siguiente: "Vamos, pues, y forjemos en teoría el Estado desde su comienzo [arché]; aunque según parece, lo forjarán nuestras necesidades" (369c). Seguidamente, narra una historia sobre la formación de la polis que resumiremos más adelante y que le sirve para instaurar un nuevo modelo de justicia. Al terminar su relato, sostiene: "Por consiguiente, se ha cumplido perfectamente nuestro sueño, por el cual (...) presentíamos que, tan pronto como comenzáramos a fundar el Estado (...) daríamos con un principio [arché] y un molde de la justicia" (443b-c).

Este interés en plantear un origen de la configuración de la polis es similar al intento de Hesíodo por relatar, desde sus inicios, el surgimiento de los dioses (y de todo lo que existe). En la Teogonía, las Musas, hijas de Zeus, narran la genealogía de los dioses desde el principio, cuando existía el Caos. Veamos el verso 45 ${ }^{1}$ : "Ellas [las Musas], lanzando al viento su voz inmortal, alaban con su canto primero, desde el origen [arché], la augusta estirpe de los dioses...". Más adelante, cuando el poeta invoca a las hijas de Zeus, declara lo siguiente: "Inspiradme esto, Musas, que desde un principio [arché] habitáis las mansiones olímpicas, y decidme lo que hubo antes de aquellos [dioses]" (v.114-115). Ahí concluye el proemio y se inicia la cosmogonía. Roxana Martínez resalta que 
todas las cosas que surgen en el relato siguen un orden temporal. "En los dieciséis versos que forman la cosmogonía propiamente dicha se hace referencia al tiempo veladamente, por medio de los verbos específicos utilizados y las partículas temporales que aparecen en ellos" (Martínez, 2000: 44). En esa misma línea se encuentra Thomas Kratzert, quien comenta que Hesíodo busca claramente un origen temporal: el poeta se pregunta, en su teogonía, qué había en el principio (Kratzert, 1998: 8). Así, se remonta a un origen primero a partir del cual establece un orden cronológico de todas las entidades presentes a lo largo de su relato.

Corresponde preguntarse, no obstante, si la noción de arché es la misma para Platón y Hesíodo. En el Timeo, 28b, el autor narra una cosmología y sostiene que, acerca del universo, "debemos indagar primero, lo que se supone que hay que considerar en primer lugar en toda ocasión: si siempre ha sido, sin comienzo de la generación, o si se generó y tuvo algún inicio". Con este pasaje, donde aparece la noción de arché, Platón sugiere un inicio claramente temporal. No obstante, en el relato sobre la fundación de la polis, creemos que Platón se aleja de esta forma de concebir el principio; es poco probable que esté proponiendo un origen histórico o un proceso evolutivo del Estado ideal ${ }^{2}$. Se trata, más bien, de una construcción teórica de la polis. En palabras de Sócrates: "si contempláramos en teoría un Estado que nace, ¿no veríamos también la justicia y la injusticia que nacen en él?" (Rep. 369d).

Así, la genealogía que narra es una suerte de experimento mental - herramienta pedagógica que le sirve para explicar la conformación de una polis justa. En relación con este tema, Vernant precisa: "toda genealogía es al mismo tiempo, e igualmente, explicación de una estructura; y no existe otro modo de explicar una estructura que presentarla bajo la forma de un relato genealógico" (Vernant, 1973: 24). Platón es consciente entonces del valor educativo de los mitos. Por ello, el relato genealógico le resulta útil en su tarea de formar a los ciudadanos con un modelo adecuado de la estructura de la polis justa.

\footnotetext{
2 Popper, en cambio, sí encuentra un proceso evolutivo que, en su opinión, explicaría la aparición de las cuatro formas deficientes del Estado: la polis perfecta deviene timocracia; luego, oligarquía; seguidamente aparece la democracia; y, por último, tiranía (Popper, 1967: 5867).
} 
Es momento de resumir la historia de la formación de la ciudad narrada en la República. Platón estima que para satisfacer las necesidades básicas del ser humano, un Estado requiere de cuatro o cinco personas. En esta pequeña ciudad, en la que habitan labradores, constructores y artesanos, cada uno está encargado de realizar una función de acuerdo con sus disposiciones naturales. A medida que el Estado va creciendo, aumentan también sus demandas. Se hace indispensable la presencia de mercaderes y comerciantes que se ocupen de importar y exportar productos. El organismo así formado es una polis idílica, con paz integral. Sus habitantes "estarán a gusto en compañía y no tendrán hijos por encima de sus recursos, para precaverse de la pobreza o de la guerra" (372b-c). Pero cuando la búsqueda del lujo se apodera de los habitantes, la polis necesita expandirse. Aparecen entonces la guerra y la clase militar. A ella pertenecen los hombres que son "mansos con compatriotas y feroces frente a sus enemigos" (375c). Y quien, además de esto, sea también filósofo, se podrá convertir en un buen guardián ( $\varphi \dot{\lambda} \lambda a \xi)$ de la ciudad (376c).

Hay dos elementos que cabe resaltar en esta historia. Primero, se revela el modelo de justicia propuesto por Platón, que consiste en la correspondencia entre la naturaleza humana y su función (Cfr. Rep., 370b). En el Estado platónico, cada uno debe especializarse en desarrollar una tarea acorde con sus disposiciones naturales. Lo segundo que merece ser destacado es el rol del filósofo. Platón considera que la unidad y armonía de la polis se garantizan cuando el poder político y la filosofía coinciden, es decir, cuando el gobernante es un filósofo (Cfr. Rep., 473d).

Para desarrollar los dos aspectos mencionados, es necesario reproducir el relato mediante el cual Platón detalla la estructura del Estado ideal:

Pero el dios que os modeló puso oro en la mezcla con que se generan cuantos de vosotros son capaces de gobernar, por lo cual son los que más valen; plata, en cambio, en la de los guardias [ع’пікоupoı], y hierro

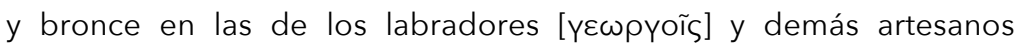

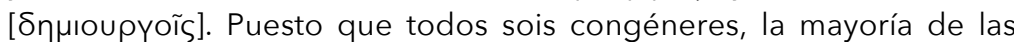
veces engrendraréis hijos semejantes a vosotros mismos, pero puede darse el caso de que un hombre de oro sea engendrado de un hijo de plata, o de uno de plata uno de oro, y de modo análogo entre los hombres diversos. En primer lugar y de manera principal, el dios ordena a los gobernantes que de nada sean tan buenos guardianes [ $\varphi \dot{u} \lambda a \kappa \varepsilon \varsigma]$ y nada vigilen tan intensamente como aquel metal que se 
mezcla en la composición de las almas de sus hijos. E incluso si sus propios hijos nacen con una mezcla de bronce o de hierro, de ningún modo tendrán compasión, sino que, estimando el valor adecuado de sus naturalezas, los arrojarán entre los artesanos o los labradores. Y si de estos, a su vez, nace alguno con mezcla de oro o plata, tras tasar su valor, los ascenderán entre los guardianes o los guardias, respectivamente, con la idea de que existe un oráculo según el cual el Estado sucumbirá cuando lo custodie un guardián de hierro o bronce (Rep., 415a-d).

Aquí aparece más claramente la idea según la cual a cada naturaleza ( $\varphi$ úøı) corresponde una función propia. La polis queda así dividida en tres grandes sectores: el de los filósofos gobernantes, en cuya alma predomina el oro; el de los guardias militares, hombres con naturaleza de plata; y el sector de artesanos, campesinos, comerciantes y trabajadores en general, en quienes destaca el bronce o hierro.

Este relato de los metales alude claramente a un mito de Hesíodo, presente en Los trabajos y los días ${ }^{3}$. Luego del himno que entonan las Musas, el poeta narra una leyenda sobre la evolución de las diversas generaciones de seres, cada una de las cuales se identifica con un metal -a excepción de la era de los héroes ${ }^{4}$. El mito se inicia de la siguiente manera:

\footnotetext{
Si quieres, yo coronaré para ti mi cuento con otro, diestra y hábilmente, y fíjate tú en el pecho cómo de lo mismo han nacido dioses y hombres mortales. Primeramente, una raza áurea de hombres con habla crearon los inmortales que tienen moradas olímpicas. En tiempo de Cronos, cuando reinaba en el cielo, ellos fueron; como dioses vivían, con el alma sin penas, bien lejos de dolor y fatigas, y vejez miserable nunca encima tenían, mas siempre -en los pies y manos igualesen banquete alegrábanse, de todos los males aparte; y morían cual por el sueño domados. Todos los bienes tenían: la tierra dadora de mieses fruto llevaba $\ldots$

Mas desde que encubrió a esa raza la tierra,
}

\footnotetext{
${ }^{3}$ Utilizamos la traducción de Paola Vianello de Córdova (México D.F.: UNAM, 1986).

4 Bruno Snell nota que hay una descripción de la decadencia de la humanidad, pero una ausencia de preocupación por las razones de su hundimiento (Snell, 1965: 83). Según Kirk, un elemento central de esta decadencia es la adhesión a la hybris (Kirk, 1973: 267-278). Sin embargo, Vernant nota que el proceso de decadencia no es continuo, básicamente por dos razones: primeramente, porque se ve interrumpido por la introducción de una raza de héroes que es superior a la precedente; en segundo lugar, porque Hesíodo no sostiene que la tercera raza sea inferior a la anterior (Vernant, 1973: 25-26). Ahora bien, no es esta la ocasión para revisar las diversas explicaciones en torno al mito ni para enumerar las dificultades que encierra su interpretación. Intentaremos solamente resaltar los elementos que nos parecen más relevantes en función de los propósitos del presente trabajo.
} 


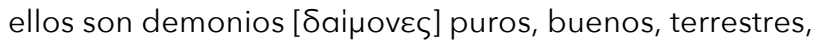

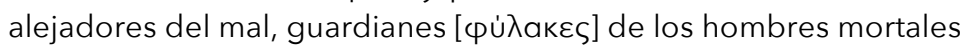
(v. 106-117; 121-123)

Como se puede notar, quienes pertenecen a la primera raza, hecha de oro, viven lejos del sufrimiento. Hesíodo los denomina "guardianes" ( empleada luego por Platón para referirse a los gobernantes. Pero volvamos al relato:

Una segunda raza, muy inferior, aún crearon después, argéntea, los que tienen moradas olímpicas,

a la áurea ni en la forma, ni semejante en la mente (v.127-129)

Los hombres que pertenecen a esta segunda raza se caracterizan por su carácter imprudente e insensato, es decir, es decir, por cierta forma de hybris. Hesíodo señala que ellos murieron siendo jóvenes y que sufrían "por su insensatez, pues no podían la temeraria violencia entre sí detener, y a los inmortales servir no querían" (v. 133-135).

Luego vienen los seres de naturaleza broncínea, de gran fortaleza. Sobre ellos, dice lo siguiente:

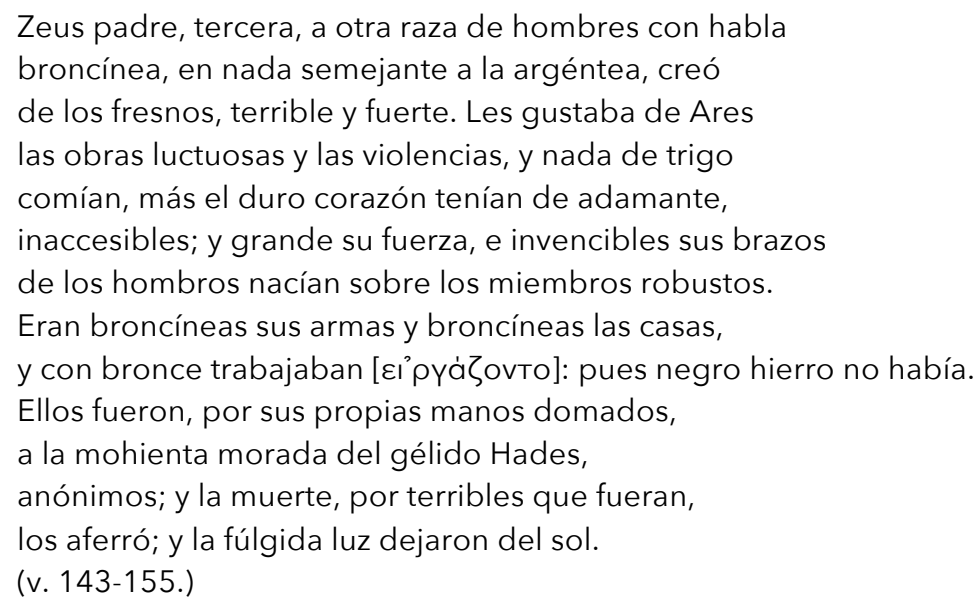

Para finalizar, describe a los hombres de hierro, con cuya raza se identifica el poeta:

¡Ojalá entre los quintos hombres ya no más estuviera, sino que antes muerto o después hubiera nacido!

Porque ahora en verdad la raza es de hierro; y nunca en el día cesarán de dolor y fatiga, y nunca en la noche de perecer; y graves les darán los dioses angustias (v. 174-178) 
Las similitudes entre los relatos de Platón y Hesíodo son notables, y las haremos más explícitas enseguida. Empecemos por los dos últimos grupos. El de hierro, según Vernant, se identifica con los agricultores pues el origen de sus males radica en Pandora, la divinidad de la fecundidad y de la tierra (Vernant 1973: 42-43). El de bronce es semejante al grupo de los artesanos. En general, las razas que, según Hesíodo, trabajan con bronce y hierro, se corresponden con quienes en el Estado platónico construyen casas y producen alimento, vestimenta y el resto de bienes básicos.

El grupo de hombres de plata es análogo al de los guardias militares de la polis de Platón. El filósofo toma en cuenta que en el relato hesiódico, la naturaleza argéntea -pese a ser inferior a la de oro- recibe también ciertos honores. Por eso, los guardias son auxiliares de los gobernantes. Presentan un carácter orgulloso y arrebatado en la adolescencia, que luego debe moldearse para devenir valiente. Poseen, además, una fuerza física que los convierte en los más aptos para resguardar la polis. Sin embargo, la fortaleza y el ímpetu propios de su espíritu no pueden llevarlos a comportarse abusivamente frente a sus ciudadanos. Platón hace una analogía entre estos hombres y los perros guardianes del rebaño: así como el pastor no espera que sus canes se dejen llevar por el hambre y ataquen a las ovejas, del mismo modo "debemos vigilar por todos los medios que los guardias no se comporten así frente a los ciudadanos, y que, por el hecho de ser más fuertes que ellos, no vayan a parecerse a amos salvajes en vez de a asistentes benefactores" (Rep., 416b). El guardia debe, entonces, tener la capacidad de moderar su fogosidad y su fuerza. Para ello requiere de una buena educación, orientada tanto a moderar su fogosidad como a desarrollar creencias legítimas sobre lo bueno, lo malo y lo temible.

Por último, los hombres de raza áurea aluden a los filósofos gobernantes que presiden este orden jerárquico. Son pocos quienes están llamados a ejercer dicha labor, pues no todos tienen la disposición ni el conocimiento requeridos para eso: "al sector más pequeño por naturaleza le corresponde el único de estos tipos de conocimiento que merece ser denominado 'sabiduría' [oopiav]", sostiene Platón (Rep., 429a). Es justamente el filósofo quien, en la famosa alegoría de la caverna, logra desencadenarse y acceder a una verdad superior que los demás ignoran. Así, la naturaleza asigna a ciertos hombres las capacidades para ejercer la 
función de guardianes, y son ellos quienes con sensatez y justicia deben gobernar la polis, pues "el mayor de los castigos es ser gobernado por alguien peor" (Rep., 347c).

Para realizar su tarea adecuadamente, el guardián debe seguir una formación extensa y dedicada. Su sabiduría implica una suerte de conversión del alma para aprehender el bien y actuar virtuosamente, es decir, en beneficio de la polis y guiado por las necesidades de esta en su conjunto. En ese sentido, se diferencia radicalmente del tirano, quien solo actúa para favorecerse a sí mismo. Al respecto, el Sócrates de la República aclara a Trasímaco, en 342e, que el gobernante justo no hace lo que conviene al más fuerte (en el caso del tirano, es él mismo); por el contrario, examina "lo que le conviene al gobernado y a aquel para el que emplea su arte".

Platón también se refiere a los guardianes de la polis como

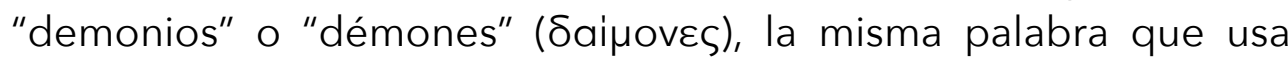
Hesíodo para los hombres de oro. En el Crátilo (398a-c), sostiene que el poeta les da esta denominación porque la raza de oro nació hermosa y noble. Entonces, si alguien hoy en día es bueno, prudente y sensato, recibirá también el apelativo de "demon", continúa el filósofo.

El gobernante debe conservar la unidad de la polis y evitar el desorden, la ruptura: la stasis, uno de los grandes males del Estado (Cfr. Rep., 351d-352). Y para eso, insistimos, tiene que vigilar que los ciudadanos cumplan con sus funciones específicas: "De este modo, al ocuparse de lo único que le es adecuado, cada uno llega a ser uno y no múltiple, y así el Estado íntegro crece como uno solo y no múltiple" (Rep., 423d). Efectivamente, cuando se realizan tareas para las cuales uno no tiene las cualidades idóneas o se desempeñan muchas funciones diferentes, la polis corre el riesgo de entrar en un proceso de desorden o descomposición.

Resulta necesario advertir en este momento que la estructura del Estado platónico es análoga a la del alma. Veamos el siguiente pasaje:

"...así como el Estado se divide en tres sectores, también el alma de cada individuo se divide triplemente [...]: Con una parte decimos que el hombre aprende, con otra se apasiona; en cuanto a la tercera, a causa de su multiplicidad de aspectos, no hemos hallado un nombre peculiar 
que aplicarle, sino que la hemos designado por lo que predomina en ella con mayor fuerza: la hemos denominado, en efecto, la parte 'apetitiva'" (Rep., 580d-e).

Este último sector del alma está orientado hacia la comida, la bebida, las riquezas, los placeres. Como se puede observar, hay un lado racional tanto en el alma como en la polis, que es el que gobierna y se asocia con el oro. Luego está la parte irascible o fogosa, relacionada con los militares y representada por la plata. Finalmente, el bronce y el hierro, correspondientes a los trabajadores, aluden a la parte apetitiva del alma.

Es conveniente precisar que todo ser humano tiene el alma tripartita. Entonces, cuando Platón se refiere a un hombre de naturaleza áurea, está sugiriendo que destacan en él aquellas cualidades vinculadas con el lado racional del alma. Evidentemente, el filósofo también dispone de características de plata o hierro, solo que su función de gobernante se determina a partir de lo más excelente en él (la razón). De modo análogo, el hombre de plata posee oro y hierro en su composición (un militar no deja de ser racional ni carece de apetitos); sin embargo, resaltan en él las cualidades propias del lado fogoso del alma, como la rudeza y la valentía (Cfr. Rep., 410d). Finalmente, así como el tercer sector del alma está orientado a la satisfacción de necesidades básicas, en el último grupo de la polis destacan ciertas características idóneas para los trabajos de producción de bienes y servicios elementales: artesanía, pastoreo, agricultura, construcción, comercio, etc.

Esta jerarquía de la polis, liderada por el filósofo, nos recuerda a la que preside Zeus, el dios que sobresale entre los demás. Hesíodo muestra la primacía de esta divinidad como producto de una victoria sobre las demás: "Reina aquel sobre el cielo y es dueño del trueno y del llameante rayo, desde que venció con su poder al padre Cronos", dice en la Teogonía (v. 71-73). El poder de Zeus le permite actuar como un rey que organiza el mundo, que pone las cosas en su lugar. Como bien nota Vernant, en las teogonías se expresa el ordenamiento del universo en términos de una jerarquía de poderes encabezada por un único agente (Vernant, 1973: 92 93). En el caso del relato de Hesíodo, el orden que instaura Zeus se presenta como un orden justo.

Todos fijan en él su mirada cuando interpreta las leyes divinas con rectas sentencias y él con firmes palabras en un momento resuelve 
sabiamente un pleito por grande que sea. Pues aquí radica el que los reyes sean sabios, en que hacen cumplir en el ágora los actos de reparación a favor de la gente agraviada fácilmente, con persuasivas y complacientes palabras. (Teog., v. 84-90).

Tal como sucede con el gobernante platónico, Zeus tiene el mayor poder, pero es también el más respetuoso del derecho. En él, precisa Vernant, se reconcilian la astucia inteligente, la fuerza del guerrero, el reparto equitativo de honores y la fidelidad a las convenciones (Vernant, 2002: 136). La función soberana de Zeus se asemeja entonces a la labor de los hombres de oro mencionados en Los trabajos y los días (Cfr. Vernant, 1973: 31). Al igual que en la Teogonía, en este último texto sobresalen las "rectas sentencias que, por venir de Zeus, son las mejores" (v. 35). Zeus se diferencia así de su padre Cronos, quien ejerce la soberanía por medio de un poder violento. Bruno Snell recuerda al respecto que todas las cosas terribles sucedieron antes de que llegara Zeus a poner orden y justicia (Snell, 1965: 79).

Es necesario mencionar también, a propósito de la teogonía hesiódica, que sus elementos están inmersos en una totalidad bien organizada: todos los miembros se relacionan mutuamente, y cada uno de los dioses realiza su propia tarea (Cfr. Gigon, 1980: 27-29). Esto sucede porque Zeus distribuyó bien las prerrogativas entre las divinidades; con ello, estableció un orden estable y permanente. Hesíodo precisa que existe asimismo una complicidad solidaria entre los reyes y agricultores (Cfr. Vernant, 1973: 49). De esta manera, en la jerarquía encabezada por Zeus, cada integrante ocupa un espacio, y todos se vinculan entre sí, como miembros de un gran organismo ordenado.

En síntesis, hemos mostrado que Platón recurre a Hesíodo tanto para elaborar un historia sobre el origen de la formación del Estado como para explicar los diversos sectores que lo conforman. Ambos elementos le resultan útiles al filósofo. Por un lado, la búsqueda de un arché le permite desarrollar una narración sobre la polis y, partir de esta, identificar los elementos necesarios para su composición ideal. El relato platónico desemboca en el gobierno del filósofo, quien -al igual que Zeus- implanta un orden justo. Por otra parte, hemos advertido que tanto el gobernante platónico como Zeus presiden una jerarquía en la que cada integrante cumple una función específica de acuerdo con su 
naturaleza. Los principales roles que desempeñan los ciudadanos en la ciudad de Platón están determinados por ciertas disposiciones de su alma y representados por los metales del mito hesiódico de las razas. Solo cuando cada miembro de este gran organismo que es el Estado cumple con excelencia la función para la que está dotado, la polis crece como una unidad armónica y justa.

\section{BIBLIOGRAFÍA}

Aristóteles (1982) Metafísica (ed. trilingüe de Valentín García Yebra), Madrid: Gredos.

Aristóteles (1994) Metafísica. Madrid: Gredos.

Gadamer, Hans-Georg. (1997) Mito y razón. Barcelona: Paidós.

Gigon, Olof. (1980) Los orígenes de la filosofía griega. Madrid: Gredos.

Hesiod (1977) Theogony. Oxford: University Press.

Hesíodo (1986) Los trabajos y los días. México D.F.: UNAM.

Hesíodo (1978) Obras y fragmentos. Madrid: Gredos.

Jaeger, Werner. (1957) Paideia. México D. F.: F.C.E.

Kirk, G.S. (1973) El mito: su significado y funciones en las distintas culturas. Barcelona: Barral.

Kratzert, Thomas. (1998) Die Entdeckug des Raums, von hesiodischen "chaos" zur platonischen "chōra". Amsterdam; Philadelphia: Grüner.

Lloyd-Jones, Hugh. (1983) The justice of Zeus. Berkeley \& L.A.: University of California Press.

Martínez Nieto, Roxana. (2000) La aurora del pensamiento griego. Las cosmogonías prefilosóficas de Hesíodo, Alcmán, Ferecides, Epiménides, Museo y la Teogonía órfica antigua. Madrid: Trotta.

Platón (1999) Crátilo, en: Diálogos, Tomo II. Madrid: Gredos.

Platón (1970) Fedro. Madrid: Instituto de Estudios Políticos.

Platón (1998) República, en: Diálogos, Tomo IV. Madrid: Gredos.

Platón (1971) República. México D.F.: UNAM.

Platón (1997) Timeo, en: Diálogos, Tomo VI, Madrid: Gredos.

Platón (1973) Oeuvres completes, Vol. X. Paris: Les Belles Lettres. 
Popper, Karl (1967) La sociedad abierta y sus enemigos, I. Buenos Aires: Paidós.

Snell, Bruno. (1965) Las fuentes del pensamiento europeo. Madrid: Razón y fe.

Szlezák, Thomas. (1991) Leer a Platón Madrid: Alianza Editorial.

Vernant, Jean-Pierre. (2002) Entre mito y política. México D.F.: F.C.E.

Vernant, Jean-Pierre. (1965) Los orígenes del pensamiento griego. Los orígenes del pensamiento griego. Buenos Aires: Eudeba.

Vernant, Jean-Pierre. (1973). Mito y pensamiento en la Grecia antigua. Barcelona: Ariel. 